\title{
PATELLAR RESURFACING VERSUS RETENTION IN TOTAL KNEE ARTHROPLASTY
}

\author{
JULIAN A. FELLER, R. JOHN BARTLETT, DEREK M. LANG
}

From the Austin Hospital, Melbourne, Australia

We studied 40 patients in whom the patella was not severely deformed and who were undergoing primary total knee arthroplasty (TKA) for osteoarthritis by one surgeon using one type of prosthesis. They were randomly allocated either to have the patella retained or resurfaced with a cemented, all-polyethylene component regardless of the state of the patellar articular cartilage. Apart from removal of osteophytes, no surgery was undertaken on the retained patellae. All 38 surviving patients were evaluated at three years using the HSS knee score and a new, specifically designed Patellar score (maximum score of 30). No TKA was revised, but two patients in the resurfacing group had a further unrelated procedure.

The mean HSS and Patellar scores at follow-up were 89 and 28 in the patellar retention group and 83 and 26 in the patellar resurfacing group. Statistically significant lower scores for both were recorded in women and in heavier patients. Stair-climbing ability was significantly better in the retention group. Although there were no complications related to patellar resurfacing, in the medium term we did not find any significant benefit from resurfacing the patella during TKA for osteoarthritis if it was not severely deformed.

J Bone Joint Surg [Br] 1996;78-B:226-8.

Received 26 May 1995; Accepted after revision 13 October 1995

J. A. Feller, FRACS, Orthopaedic Surgeon

R. J. Bartlett, FRACS, Senior Orthopaedic Surgeon

D. M. Lang, FRCS, Orthopaedic Fellow

Department of Orthopaedics, Austin Hospital, Studley Road, Heidelberg 3084, Melbourne, Victoria, Australia.

Correspondence should be sent to Dr J. Feller at Suite 1, 210 Burgundy Street, Heidelberg 3084, Melbourne, Victoria, Australia.

(C)1996 British Editorial Society of Bone and Joint Surgery 0301-620X/96/21153\$2.00
The need to resurface the patella as part of a total knee arthroplasty (TKA) remains controversial, and there are relatively few reports of controlled series. Most of these deal either with specific circumstances (Shoji, Yoshino and Kajino 1989) or with advanced disease (Enis et al 1990). Others include mixed groups in terms of diagnosis, surgeon or prosthesis (Abraham et al 1988; Boyd et al 1993; Levitsky et al 1993; Keblish, Varma and Greenwald 1994). The results from these reports are conflicting (Rand 1994), making it difficult to decide whether the potential benefits of patellar resurfacing of a typical osteoarthritic knee outweigh its potential complications.

We aimed to evaluate the role of patellar resurfacing in a standard TKA for osteoarthritis.

\section{PATIENTS AND METHODS}

We studied prospectively 40 patients who had a technically uncomplicated primary TKA for osteoarthritis during a sixmonth period beginning on 30 November 1990. All the operations were performed by the same surgeon in one hospital.

We excluded patients who previously had a patellar realignment operation or other major surgery such as a high tibial osteotomy. Three patients with severe deformity of the patella were also excluded at the time of operation, before randomisation. We considered that the inclusion of these patients would skew the results in favour of patellar resurfacing and fail to reflect the true outcome for the typical patella seen at TKA. The degree of damage to the articular cartilage of the patella was not a basis for exclusion but was graded according to Outerbridge (1961). The 40 selected patients were randomised equally to resurfacing or retention of the patella by the use of sealed envelopes containing the treatment allocation.

The surgical technique was similar in all cases using a medial parapatellar approach and the PCA Modular prosthesis (Howmedica, Rutherford, New Jersey). Contained bone defects of less than $10 \mathrm{~mm}$ in depth and diameter were filled with graft from the resected bone. Knees with larger or non-contained defects were excluded. The femoral and tibial components were inserted without cement, but in the resurfacing group an all-polyethylene offset-dome patellar component was cemented into position. Peripheral osteophytes were excised in both groups but no surgery was performed on the articular cartilage or subchondral 
Table I. Details of the Patellar score

\begin{tabular}{lr}
\hline & Score \\
\hline Anterior knee pain & 15 \\
$\quad$ None & 10 \\
Mild & 5 \\
Moderate & 0 \\
$\quad$ Severe & \\
Quadriceps strength & 5 \\
Good (5/5) & 3 \\
Fair (4/5) & 1 \\
Poor (</5) & \\
Ability to rise from chair & 5 \\
$\quad$ Able with ease (no arms) & 5 \\
Able with ease (with arms) & 3 \\
Able with difficulty & 1 \\
Unable & 0 \\
Stair-climbing & \\
1 foot/stair, no support & 5 \\
1 foot/stair, with support & 4 \\
2 feet/stair, no support & 3 \\
2 feet/stair, with support & 2 \\
\hline
\end{tabular}

bone of the retention group. Patellar tracking was checked at the end of the operation; no patient required any adjustment by procedures such as lateral release.

An independent investigator evaluated all patients preoperatively and at three years postoperatively, using the Hospital for Special Surgery (HSS) knee score (Insall et al 1976) and a new Patellar score (Table I). The latter allocates 30 points for anterior knee pain and 10 points for each of quadriceps strength, ability to rise from a chair and stairclimbing. Table II shows the age, gender, weight and time to review for both groups. These were similar apart from gender distribution; there were more males in the resurfacing group. The number of patients with grade I, II, III and IV articular changes were 2, 10, 5 and 2 in the retention group and 1, 11, 4 and 3 in the resurfacing group.

Table II. Details of 38 surviving patients who had TKA with or without patellar resurfacing

\begin{tabular}{lll}
\hline & Resurfacing & Retention \\
\hline Age in years (mean; SD) & $70.5(6.6)$ & $71.1(5.6)$ \\
Male:female & $13: 6$ & $8: 11$ \\
Weight in kg (mean; SD) & $86.1(13.2)$ & $78.6(14.7)$ \\
Review time in months (mean; SD) & $39.1(2.5)$ & $37.8(2.4)$ \\
\hline
\end{tabular}

Statistical analysis was undertaken by the Statistical Consulting Centre of the University of Melbourne. For the analysis of HSS and Patellar scores, three methods were used to offset the effects of imposing restrictions on data when a particular procedure was applied. These were the analysis of variance, logistic regression using a cut-off point close to the median value, and logistic regression using the middle value relative to the range of values. With the exception of alignment, fixed-flexion deformity and range of flexion, the difference between the two treatment groups was tested for each of the other individual outcome variables using Fisher's exact test.

\section{RESULTS}

One patient from each group died from unrelated causes before review. No revisions were needed in either group, but two patients from the resurfacing group had additional procedures: one had arthroscopic division of suprapatellar adhesions to restore flexion and the other had an arthrotomy because of continued posterolateral pain. No diagnosis was made and the pain subsequently resolved.

Table III. Preoperative and review values for the HSS and Patellar scores in both groups

\begin{tabular}{lllll}
\hline & Resurfacing & Mean & Median & SD \\
\hline Preoperative HSS & No & 61.6 & 61 & 10.5 \\
& Yes & 63.8 & 60 & 10.1 \\
Review HSS & No & 88.6 & 90 & 5.2 \\
\multirow{5}{*}{ Preoperative Patellar } & No & 85.7 & 87 & 7.0 \\
& Yes & 19.9 & 20 & 3.3 \\
Review Patellar & No & 27.7 & 21 & 3.7 \\
& Yes & 25.6 & 30 & 3.9 \\
& & & & 4.8 \\
\hline
\end{tabular}

Table III gives the preoperative and review HSS and Patellar scores. Both the resurfacing and retention groups showed a statistically significant improvement, but we found no such correlation between preoperative and review scores within each group or in the whole series. There was no correlation between the review score and the background variables of age and grading of patellar articular cartilage.

We found no significant difference between the two treatment groups for the review HSS and Patellar scores. The calculation and comparison of $95 \%$ confidence intervals (CI) for the preoperative-to-review change in both groups resulted in non-significant $t$ values, but there was a trend towards worse HSS and Patellar scores in the resurfacing group. Both scores at review were significantly lower in women and in heavier patients $(\mathrm{p}<0.05)$. There were significantly worse scores for stair-climbing in the resurfacing group $(\mathrm{p}<0.05)$.

\section{DISCUSSION}

Our study provided no evidence to support the routine resurfacing of the patella at a TKA for osteoarthritis. Indeed, there was a trend towards poorer results for both HSS and Patellar scores in the resurfacing group.

We studied relatively small groups, but the comparison was both prospective and randomised. We minimised the number of potential variables and all surviving patients were reviewed. Our findings confirm those of four studies of patients who had bilateral knee arthroplasties with resur- 
facing of the patella on only one side (Shoji et al 1989; Enis et al 1990; Levitsky et al 1993; Keblish et al 1994). All these authors found no clear benefit in routine resurfacing, but one study dealt only with rheumatoid arthritis (Shoji et al 1989) and another included only patients with advanced patellofemoral disease (Enis et al 1990).

Levitsky et al (1993) reported a 19\% incidence of mild anterior knee pain in the absence of resurfacing of the patella, and Soudry et al (1986) had noted impaired stairclimbing ability when the patella had not been resurfaced. Enis et al (1990) found reduced isokinetic quadriceps strength in patients without resurfacing. Our Patellar score was designed to record those variables likely to be influenced by the management of the patella. In contrast to the studies reported above, our findings with regard to the Patellar score were virtually identical to those of the HSS knee score. In particular, we found that stair-climbing ability was significantly better in those patients in whom the patella had not been resurfaced. Soudry et al (1986) reported the opposite finding but found no difference in the distribution of good and excellent results between the resurfaced and non-resurfaced groups. Their finding of no difference in outcome between rheumatoid and osteoarthritic knees is consistent with our results showing a lack of correlation between the state of the patellar articular cartilage and either the HSS or Patellar scores in our retention group.

The largest study of patellar resurfacing is that of Boyd et al (1993). This was retrospective and involved ten surgeons, but the authors considered that the two groups of patients were essentially similar. The decision to resurface or not was based on the state of the patella at operation. It might have been anticipated that this would favour patellar retention which was chosen for minimally diseased patellae. Despite this there was an increased incidence of complications and chronic peripatellar pain in the retention group, and revision to resurfacing was required for 51 patients with chronic peripatellar pain at an average of just under five years. Our follow-up was only three years and it is possible that the results in our retention group may deteriorate later. Two of the four published studies of patients with bilateral procedures also had a mean followup of less than five years, but Keblish et al (1994) found no time-dependent deterioration of results after a mean followup of 5.2 years. Smith, Stuart and Pinder (1989) also reported good results for patellar retention over five years' follow-up, provided that correct patellar tracking had been achieved.

Picetti, McGann and Welch (1990) suggested resurfacing for tall and heavy patients with osteoarthritis. We did not record height but did find better overall results in lighter patients $(\mathrm{p}<0.05)$. Although men tend to be heavier than women, the latter had lower scores $(\mathrm{p}<0.05)$ which suggests that gender may be more important than weight. Despite there being more women in the retention group there was a trend toward better scores in these patients. This suggests that a more even sex distribution may have increased the difference in scores between the two groups.

The complication rate after patellar resurfacing has been suggested as a reason for caution (Bayley and Scott 1988; Rosenberg et al 1988; Stulberg et al 1988), but other studies have reported few problems, provided that good technique included satisfactory alignment of the patella (Ranawat 1986; Rae, Noble and Hodgkinson 1990; Keblish et al 1994). We had no complications at three years after patellar resurfacing, but despite this consider that our study and those previously published provide adequate evidence for retention: we do not now resurface the patella as a matter of routine for patients having a primary TKA for osteoarthritis.

No benefits in any form have been received or will be received from a commercial party related directly or indirectly to the subject of this article.

\section{REFERENCES}

Abraham W, Buchanan JR, Daubert H, et al. Should the patella be resurfaced in total knee arthroplasty?: efficacy of patellar resurfacing. Clin Orthop 1988;236:128-34.

Bayley JC, Scott RD. Further observations on metal-backed patellar component failure. Clin Orthop 1988;236:82-7.

Boyd AD Jr, Ewald FC, Thomas WH, Poss R, Sledge CB. Long-term complications after total knee arthroplasty with or without resurfacing of the patella. J Bone Joint Surg [Am] 1993;75-A:674-81.

Enis JE, Gardner R, Robledo MA, Latta L, Smith R. Comparison of patellar resurfacing versus nonresurfacing in bilateral total knee arthroplasty. Clin Orthop 1990;260:38-42.

Insall JN, Ranawat CS, Aglietti P, Shine J. A comparison of four models of total knee-replacement prostheses. J Bone Joint Surg [Am] 1976; 58-A:754-65.

Keblish PA, Varma AK, Greenwald AS. Patellar resurfacing or retention in total knee arthroplasty: a prospective study of patients with bilateral replacements. J Bone Joint Surg [Br] 1994;76-B:930-7.

Levitsky KA, Harris WJ, McManus J, Scott RD. Total knee arthroplasty without patellar resurfacing: clinical outcomes and long-term follow-up evaluation. Clin Orthop 1993;286:116-21.

Outerbridge RE. The aetiology of chondromalacia patellae. J Bone Joint Surg [Br] 1961;43-B:752-7.

Picetti GD III, McGann WA, Welch RB. The patellofemoral joint after total knee arthroplasty without patellar resurfacing. J Bone Joint Surg [Am] 1990;72-A:1379-82.

Rae PJ, Noble J, Hodgkinson JP. Patellar resurfacing in total condylar knee arthroplasty: technique and results. J Arthroplasty 1990; 5:259-65.

Ranawat CS. The patellofemoral joint in total condylar knee arthroplasty: pros and cons based on five- to ten-year follow-up observations. Clin Orthop 1986;205:93-9.

Rand JA. The patellofemoral joint in total knee arthroplasty. J Bone Joint Surg [Am] 1994;76-A:612-20.

Rosenberg AG, Andriacchi TP, Barden R, Galante JO. Patellar component failure in cementless total knee arthroplasty. Clin Orthop 1988;236:106-14.

Shoji H, Yoshino S, Kajino A. Patellar replacement in bilateral total knee arthroplasty: a study of patients who had rheumatoid arthritis and no gross deformity of the patella. J Bone Joint Surg [Am] 1989;71-A: 853-6.

Smith SR, Stuart P, Pinder IM. Non-resurfaced patella in total knee arthroplasty. J Arthroplasty 1989;4:Suppl S81-6.

Soudry M, Mestriner LA, Binazzi R, Insall JN. Total knee arthroplasty without patella resurfacing. Clin Orthop 1986;205:166-70.

Stulberg SD, Stulberg BN, Hamati Y, Tsao A. Failure mechanisms of metal-backed patellar components. Clin Orthop 1988;236:88-105. 